\title{
Healthy Ageing and Mediated Health Expertise
}

\author{
Christa Lykke Christensen
}

\begin{abstract}
The media are, for many older people, one of the most important sources of information about health. In this article, I examine older people's experiences and use of media to acquire knowledge about health issues relating to their own life. Key questions concern how media influence older people's perceptions of health and to what extent they trust the media in relation to health issues. The study demonstrates that the media do not have a uniform influence among older people. For some, the media function as a guide to maintaining and experimenting with an active lifestyle in late life; for others, the media are met with a skeptical attitude as they are not trusted as a source of reliable and unequivocal information on health issues. The study is based on a qualitative interview study with men and women between 65 and 86 years.
\end{abstract}

Keywords: media use, older people, lifestyle, active ageing, trust

\section{Introduction}

Health is a subject that is never off the agenda. It is talked about all the time and everywhere - at work, in institutions and at home - by people of all ages. Health has become a common point of reference which confers meaning on and sets the framework for our understandings of the individual in all aspects of day-to-day life. Talking about health has become a natural part of the way we articulate ourselves, a prism people see through as a matter of course when contemplating their lives. Everybody is expected to have a well thought out position on health, no matter what your age is, and thinking about health is often regarded as such an integrated part of the individual's self-perception that it becomes a benchmark for assessing not only their own success in life but that of other people as well. Health is regarded as particularly topical when talking about older generations.

This article focuses on how older people think about health, and it is based on the assumption that the media play a particularly prominent role in how older generations view health. In this context, the media can be seen as an interface between the individual citizen and society. The media convey and present results generated by institutionalised health and medical science - represented by the expertise of doctors and 
other healthcare professionals - and they act as a communication forum for citizens, e.g. via social media. In this sense, the media constitute a resource, making it possible for people to seek out, receive, mediate and share experiences of health issues to an unprecedented extent. The media are also in a position to present scientifically based content side-by-side with more popular science, ordinary people's experiences and commercial content. Using the broad concept of health as a platform, in which health is often equated with a healthy lifestyle and aspirations for 'the good life' (Otto 1997, Lewis 2006, 2008), there are almost no limits to what is considered relevant as a health theme and can be used as media content. Against this background, the mediatization of health (Christensen 2016) represents a challenge to traditional, institutionalised health expertise. Some of the functions previously carried out by doctors can to a certain extent be provided in mediated form, for example, information searches, consultations and medication. and new forms of mediated healthcare practice have emerged outside the framework of the traditional health service, heavily inspired and orchestrated by the media narrative of health as a constellation of different aspects related to 'the good life'.

It is in the light of the media's function as a cultural backdrop (Hjarvard 2016) for everyday understanding of what health is that this article will focus on how older people perceive health and how they manoeuvre within and 'negotiate' the all-encompassing range of mediated health on offer - in particular in relation to ideas about 'active and healthy ageing'. The article is based on interviews with older Danish people, and it sheds light on how they assess and deploy the health expertise to which they are exposed by the media.

The argument pursued is that the media play an important role as a discursive framework for life also for the older. In general, old people are major consumers of mass media, i.e. they listen to the radio, watch TV, and read daily and weekly papers on a daily basis (Danish Agency for Culture 2015, Nielsen \& Schrøder 2014). Like other generations, they are exposed to mediated health content, which appears almost every day in newspapers, magazines, and on TV and radio, in films and series, in printed and electronic advertisements as well as on Internet health portals, blogs, and social media. The fact that health feels omnipresent is not, therefore, due to any general degeneration in the health of the elderly, or that doctors and health authorities necessarily play a greater role in their lives than in the past. The most recent data even suggests that people live longer than ever (Jeune et al. 2015) and studies suggest that the number of years the elderly spend suffering from long-term debilitating illness has also dropped significantly in the last two decades (Christensen et al. 2013). Much of the evidence would suggest, therefore, that the importance of health has more to do with its omnipresence and visibility in the media. According to both agenda setting theory (McCombs 2014) and cultivation theory (Harris 2009, Morgan; Shanahan \& Signorielli 2012), this may, by itself, encourage people to think of health as a theme to which it is important to relate and about which it is important to have opinions. The article takes a closer look at how the elderly experience this substantial focus on health - a focus that does not necessarily link health to illness, but rather to ideas about improving the quality of life and notions of 'active ageing'. 


\section{Towards an 'all-age role'}

Before we get to the analysis, a few of the assumptions that form the basis for the study need to be clarified. Multiple studies have shown that to date the media have circulated a predominantly negative view of old age and the elderly (Hepworth 2004, Wien 2005, Williams; Wadeigh \& Ylänne 2010). However, research also suggests that the media has played an important role in the last couple of decades in presenting more 'positive' representations of the elderly as resourceful, healthy, active and productive members of society (Katz 2000, Katz \& Marshall 2003, Rozanova 2010, Marshall \& Rahman 2015). There is, therefore, no doubt about the significant role the media plays in framing (Entman 1993) the elderly as also being an active and healthy ageing part of the population. It can thus be assumed that the media's framing of the elderly as healthy and active citizens also helps to expand their views of what it means to be older, what old age is and what it can be.

The idea that the media has heightened expectations of old age and of the elderly is something that Joshua Meyrowitz argued as far back as 1985 in his book No Sense of Place. In it, he describes how the media, especially the spread of television in the second part of the 20th century, contributed to the blurring of boundaries between childhood and adulthood. In principle, developments in the media landscape have provided people of all ages with access to information and knowledge about everything, not least to knowledge relating to other age groups' experiences, lives and problems. According to Meyrowitz, this blurring of boundaries means that 'the more one learns about how people of another stage of socialization behave, the more one can select aspects of that behavior for oneself' (1985: 152). His conclusion is that 'in the long run, both adult and child roles shift toward a "middle region, all-age role" (ibid: 154). Meyrowitz argues, therefore, that media have helped cause 'significant changes in the ways children and the elderly are encouraged and allowed to behave' (ibid: 234). For the elderly, expectations of an all-age behaviour style and role conception have opened up opportunities to appropriate a purportedly more youthful lifestyle; they have (also naturally due to better finances and health) for example the opportunity to continue their adult life style into their old age and distance themselves from the often restrictive way old age is categorised. The mere possibility of this 'all-age role' has created an expectation that the elderly will not necessarily accept, but will oppose, being categorised as old-fashioned, inactive and useless.

However, Meyrowitz also points out with some reticence that the distinction between 'the elder' and 'old age' continues to be both important and socially useful, because, as he puts it (ibid: 153):

Old people today are not generally appreciated as experienced 'elders' or possessors of special wisdom; they are simply seen as sometimes remaining competent enough to be included in the unitary role category of 'active citizen'. Old people are respected to the extent that they can behave like young people, that is, to the extent that they remain capable of working, enjoying sex, exercising, and taking care of themselves.

Thus, it is now possible for the elderly to have interests and behave in ways previously reserved for younger age groups, even while the idea remains alive of old age as a phase of life populated by weak and socially unproductive individuals and, therefore, 
represents a phase of life that very few 'active citizens' look forward to. Whereas the opportunities for change and renewed growth late in life are presented on the one hand as a field of opportunity, which the elderly 'just' have to conquer, categorisations of old age, on the other hand, are still closely linked to notions of decrepitude, decline and, in the final instance, death. The conclusion is that old people are still measured by the same yardstick as the young. 'Youthfulness' continues to be the prevailing ideal, only now it is possible for the elderly to share it - at least as long as they are able to demonstrate that, as active ageing individuals, they are valid, socially useful citizens. Understood in this way, active and healthy ageing can, therefore, be seen as a normativity with negative consequences for many old people, for example those who do not want to, or are unable to, age actively, while for others the requirement for activity late in life as a health parameter may just be what makes old age worth living.

\section{Method}

With the analytical focus on older people's perceptions of mediated health, we want to concentrate on this age-related dilemma and study whether, and if so, how they experience and cope with this dilemma. We will take a closer look at the role the elderly attribute to the media, both in relation to their perceptions of active ageing and in relation to the strategies they employ to cope with mediated health.

The study is based on 16 individual, qualitative interviews (Kvale 2007, Brinkmann 2014) with four men and 12 women aged 65-86, all of Danish origin. The interviews were conducted from October to December 2014 and April to June 2015. The informants were recruited from two different suburbs of Copenhagen, the profiles of which differ in terms of parameters such as average income and levels of education and health, with one of the two ranking somewhat lower than the other. Recruitment of the informants was done proactively in day centres, gyms, old people's organisations and associations, and by means of the snowball technique. All of the informants regularly take part in activities outside the home; despite attempts it proved impossible to make contact with older people who never or rarely leave their own homes. The study is, therefore, limited to older people who are able to leave their homes and take part in activities of various kinds. All informants live in their own house or flat; seven of them with a spouse, nine alone after the death of a spouse. Due to a limited time frame and because it was easier to motivate women to take part, there is a preponderance of women in the 65+ age group. Most of the interviews were conducted in the informants' homes, some at centres frequented by the older, and some in the interviewer's office. The interviews were recorded digitally, transcribed, and the names of the informants were changed.

All of the interviews were based on a thematically structured guide (Thagaard 1998) which - in addition to questions relating to general demographic data such as age, gender, civil status and education - focused on questions related to themes such as how the informants perceived health; the relationship between health, ageing and old age; their attitude to the importance of the media to health perceptions and practices, as well as what they thought about changes in perceptions of health during the course of their lives. 


\section{Findings}

'The will to be healthy'

The argument often deployed in scientific and public debate to underline the necessity of activity in old age is the health argument. Paul Higgs et al. (2009) denote health as one of the most dominant discourses in late life and as an absolute driving force in the construction of what is known as the third age's lifestyle and forms of identity: "The will to be healthy" reflects the fact that health has become a required objective for individual behaviour and synonymous with health in itself' (2009: 687). It might also be said that health has become synonymous with the actual willingness and the desire to work on becoming healthy, rather than health being an expression of an end status individuals can find themselves in of being healthy. In other words, health requires reflection on how you can and should actively relate to your own health.

The interviews in this study showed that the elderly all agree that ageing and health belong together; that health involves a conscious effort to become healthy and improves your chances of a good old age. For example, a 79 years old woman, Grethe, on health: 'Yes, it is, of course, about living an active life and eating more or less sensibly', and Svend (76) says: 'It has to do with lifestyle, and lifestyle covers a lot of things, doesn't it - the way you eat and so on - how you put together your meals and how many of them you eat.'

Diet and exercise play an important role in all of the informants' thinking on health. Thus, when they talk about health, it is only something relevant in a 'close' and personal health perspective. The informants also more or less agree on their expectations of growing old. It is almost a moral obligation that despite advancing years you ought to remain committed to your own life, you ought to still be active and maintain yourself and your body. 'Health for me - it's activity; it's keeping active, going to things and keeping an eye on your diet', says Sonia (74).

The elderly thus indicate a 'willingness to be healthy' in their demand to retain their bodies and their self-respect. They assure the interviewer repeatedly that it is a big challenge but also important for them to master life again -i.e. in a new situation, in retirement, and for some of them alone after the loss of a lifelong partner or close friends. They also want to deal with their own general expectations - and those of other people and society - that life should continue to be meaningful and worth living. In the interviews, this is mainly expressed in their active attitude to life. The older do not think that age in itself should be a barrier to 'growing', 'keeping themselves going' and living life to the full. This expectation of old age is consistent with the understanding they have of themselves as people who lead a healthy life. As a result, they have a considered approach to ideas about active and healthy ageing. However, as we will see, both health and ageing give rise to various types of practice and reflection - not least under the influence of mediated health, to which they have to relate on a day-to-day basis.

\section{Different strategies}

As the informants of the study were between 65 and 86 years old, there were different ways of considering and practising health among them. In this context I will, however, focus on two, partly different, health strategies present in the material. These strategies are not representative of all informants; nonetheless they point at particularly important 
perceptions of health and ageing among those interviewed. The two health strategies identified also reflect different attitudes to mediated health.

One group wants to and endeavours to maintain a certain level of activity from their earlier adult life into late life, not taking into account that they have grown older. The main purpose of their activity is to ward off signs of ageing. This group are keen users of the media's frequently changing health messages. The other group thinks that in retirement they - so to speak - have to re-invent themselves again as active older individuals, not to, necessarily, ward off signs of ageing or extend middle life, but to verify the expectations of the world around them (and themselves) that they ought to be active in old age. At the same time, they reconcile themselves with their advancing years and, by necessity, with a certain degree of decline. This group has a more sceptical attitude toward mediated health than the first one.

These two strategies for ageing (Maintaining activity into late life and Re-inventing yourself as an active older individual) can be related to the distinction Higgs et al. (2009) make between the idea of normal ageing and natural ageing. Normal ageing is associated with wanting to preserve some specific norms for how to maintain your body and mind at any given point in time, in order to defer or deny decline, which looms on the horizon. By contrast, the natural ageing process is connected with a higher degree of acceptance of growing older and ageing, and thus with a certain acceptance of physical decline.

\section{Maintaining activity into late life}

One example of the first strategy, according to which levels of activity are not affected by age, is Karen (69), who goes to the gym 2-3 times a week, plays golf, skis and goes for walks. She stresses several times how important her planned activities are to her and how much control she would like to have over her body. She underlines that it is important to her to maintain a high level of activity and expresses great awareness of her diet:

I live very healthily, i.e. [laughs] I start my day on a smoothie made of beetroot, pineapple and almond milk, or some such, berries or spinach omelette, and in the evening it's always the same, lots of vegetables, maybe with grated beetroot and some meat. Yes. In other words, I think about my diet all the time: What is it that I'm stuffing into myself? I don't eat any gluten or lactose, for example. My stomach's a little bit delicate, and I found out that I feel much better when I don't eat that kind of stuff. So I bake my own gluten-free bread, for example. I do.

Karen is highly aware of her dietary habits, which are carefully planned and have the appearance of a programme to which she has to adhere. The sense of duty is underlined by the fact that she and her husband once in a while agree to 'take a break' from the programme: 'Well, when we're at a party, we're at a party, you know. The next day, we start again, you know.'

Another woman, Kirsten (66) stresses that she almost has a need for many activities. She goes to gymnastics twice a week, plays badminton and golf once a week, and goes to the gym, because, as she puts it: 'You have to do something.' Asked about her motivation for this high level of activity, Kirsten replied: 'I go to gymnastics on a Tuesday because I know I don't have many years left, so keeping my body going seems like a good idea.' Karen also spoke about what motivates her fitness 'programme': 
Karen: Well, it's something to do with really wanting to keep myself healthy (...) I'm very much into putting the right things into my body. I am.

Interviewer: Why do you do it?

Karen: Because I think it makes me feel good. That's all: I have some idea [laughs] that living healthily might extend my life a little.

Interviewer: And you want to live for a long time?

Karen: Yes, I do, but also to feel good.

For Karen, the duties inherent in an active lifestyle belong to everyday life as part of a project that she has to work on all of the time and under controlled conditions. As she puts it: 'I really want to stay healthy', which underlines the seriousness of her daily project to maintain herself in the condition she is in now, expressed in terms of 'keeping myself healthy'. Both women are conscious of risk and view their chosen lifestyle as a form of investment, the return on which they hope will be in the form of a longer life. Several times, Karen gives expression to the uncertainty associated with growing old: 'Yeah well, okay, you should be happy that you're able to live a healthy life and exercise. But you don't know for how long. You just don't. Not at all, at all.' Even though Karen means that she ought to be happy that she 'can live a healthy life and exercise', it is very much a joyless affirmation. Rather she gives the impression that she sees her life as a brief respite, and the uncertainty about what the future may bring casts shadows over the present. You get the sense that instead of enjoying the 'freedom' that comes with old age, she is afraid of ending her days as a fragile, old woman with no control over her own body.

Uncertainty as a motivation to fight back against progressive decline was also evident in Jette (70), who also expressed concern about the uncertainty that the future holds and cited life expectancy statistics as an argument in favour of living more healthily:

When I turned 60, I started to think more about the idea that if I was to last as long as the statistics say, I would have to get a grip. I don't want to, and I mean it sincerely, I really don't want to be just another couch potato, getting fatter and fatter and lazier and lazier and just saying: 'it hurts here, and here and there', and that sort of thing.

Jette knows rationally that she 'ought to get a grip' if she wants to live as long as the statistics for life expectancy suggest she should. Even though she talks of living very healthily, she also says that when she feels bad or sad she eats far too much and all of the wrong things - something that feels like a bit of a failure in terms of 'getting a grip'. 'I think that your emotions dictate your eating a bit', she says, but has sufficient self-insight and awareness to realise that there is 'no comfort in cookies'. She is caught in a dilemma between norms, statistics, morals and expectations on the one hand, and emotions and physically uncontrollable needs on the other.

The three women quoted above are examples of ageing strategies in which the abstract desire for a 'longer life' represents a norm and a logic that makes the women personally responsible and, in Jette's case, morally responsible for minimising as many as possible of the risks that might lead to physical decline and death. Their daily striving to extend time (before death) becomes an attempt to stop time and perpetuate the condition they are in here and now. It might be said that their efforts reflect the paradox 
that Alftberg \& Lundin highlight in their study of older people's experience of ageing, namely that 'people want a long life, but do not want to be old, or rather: they want to be old in a very particular way' (2012: 493) - a way that Alftberg and Lundin describe as 'successful ageing'.

Similarly, the women quoted above may well want to live for a long time but they refuse to allow the ageing process to take a hold of their bodies. When asked, however, they express no desire to look young or youthful. Nevertheless, they see ageing as a dilemma, and are frustrated by the transition to being physically old and their inability to stop the process. When Karen is asked if she feels younger than she actually is, she replies in the affirmative: 'Of course, I know that I look old in the mirror, but I do feel much younger. That's why it annoys me that I'm seen as old because I feel younger, you know. Yes, that is annoying!' She may well recognise the signs of ageing on her body, but on the other hand she is unable to reconcile herself with the thought of actually looking older. She craves acknowledgement for her 'inner' youthfulness, and not to be judged on her actual age, as revealed by her body.

It might be said that she and the other two women (as well as several others who took part in the study) are exponents of the idea of 'normal ageing' (cf. Higgs et al. 2009). In their efforts to live a healthy life they mobilise persistently - but with differing results their bodies as the resource which shows that - despite their age - they can still cope with a high level of activity that they hope will stave off physical decline. Their strategies for ageing centre around activities designed to minimise the risk of lifestyle-related diseases and death, rather than to make them happy about their bodies as they are or about life in general. In that sense, it might be claimed that these women over-compensate when it comes to complying with prevailing norms for how a health practice should manifest itself in the form of active and successful ageing.

\section{The media as a guide}

What is interesting is that the same women (and several others in the study) unequivocally identify the media as a resource that plays a crucial role in the maintenance of their healthy lifestyle. Karen says, for example:

I read - I swallow any useful tips I can pick up. I read anything I can get my hands on. I mean I don't buy your actual women's magazines - but if I do read them, those are the pages [about health and diet] I look up right away, you know. I get Health, so I read it as well, you know. Yes, I'm really into only putting the right things into my body. I am.

Karen reflects almost a greed for media content that will instruct her in the ways of a healthy lifestyle. She trusts the media, saying that they point her in the direction of 'putting the right things' into her body, and she energetically seeks out media content with which to experiment. When asked about the media narrative on health and their influence in general, she replies that she has a positive view of the media because they 'reach out to ordinary people who aren't experts'. She is not at all tired of the media preoccupation with health, on the contrary she says: 'I just can't get enough of it. No, no, no.' Similar to several of the other informants, Karen is informed, proactive, makes choices, experiments with the help of the media, and she represents the type of reflexive consumer that Henwood et al. (2003:597) characterise as wanting 'to take more 
and more responsibility for their own health and $[\ldots]$ this involves active information searching, above and beyond the traditional visit to the doctor'. Though the informants have a computer/tablet, they do not mention it in this context. They are not interested in information on illness, but in health-related topics they may use to improve their own health condition.

A similar faith in mediated health expertise is expressed by Jette, an avid viewer of TV programmes about health, and, in particular, obesity, diet and exercise. She is such a big fan of two TV health 'gurus', Chris MacDonald and Christian Bitz, that she attends lectures they give in Copenhagen. When asked why she is interested in them, she replies: 'Well, it's because I like their philosophy of life, and I think it's important to keep yourself going, you know. I think it's important to live a healthy life.' Jette listens to media experts' advice and 'philosophy' and knows what she ought to think about health, in the same way as she measures her own life against life expectancy statistics and, therefore, has a benchmark for how long she should be able to live.

As mentioned previously, Jette (and several others in the study) have problems living up to the design for 'normal' or 'successful' ageing propagated by the media. She is not capable - unlike others such as Karen - of following the instructions the media issue for a healthy lifestyle. On the one hand, she sees them as norms that exert pressure on the life she leads, and which she therefore thinks that she should change. In other words, the media motivates her to change, to appear like a strong woman capable of looking after herself, someone for whom nobody should feel sorry. However, the level of effort that a lifestyle change requires is not something that she personally has the resources to implement, and she often finds herself frustrated by her lack of ability to do what the media experts (as she repeatedly calls them) believe is healthy for her. Nonetheless, the knowledge filtered through the media represents a form of expertise that she seeks out time and time again, has faith in and tries to live up to, not least because for her it represents a socially authoritative voice. However, this knowledge also places her in a dilemma, and she often has to succumb to the fact that her mind is often more capable of change than her will and emotions.

The three women mentioned above exemplify some recurring trends among the informants who are trying, albeit in different ways, to live up to ideas related to what we call the 'normal' ageing discourse, and which is based on older individuals' attempts to delay their own physical decline by living up to mediated health expertise. Some of them manage to follow the instructions in practice. They successfully base their old age on a (healthy) strict diet and a high level of activity in the hope of a longer life. In that sense they go all in. Others, however, struggle in vain and despair at their own inability to adapt their needs to fit the media advice on healthy and active lifestyles. For them, age always feels like a process over which they are not exerting control.

\section{Re-inventing yourself as an active older individual}

Another group of elderly informants are exponents of what is, in many ways, a different lifestyle - one in which health has a different status and, importantly, the media play a different role. They are, to a greater extent, examples of older people oriented toward 'natural ageing' (Higgs et al. 2009). This group also links health to diet and exercise, but they do so based on a different argument than prolonging life and disciplining the 
body, and they have a more sceptical attitude to the health expertise propounded by the media. In this sense, they seem to represent a different strategy for ageing. They refer to health mainly as a question of not being sick, i.e. they subscribe to the idea that the concept of health must necessarily be linked to a concept of ailment. Christian (73) says, for example:

By health, I think about whether you're well and mobile. That's the first thing that springs to my mind when I hear the word health. Whether or not I can do the things I ought to be able to do - my age taken into account - that's the first thing I think of. For me it's also, of course, about being mobile, being able to look after my house and garden.

This group stresses good physical condition as an important health factor, something that gives them a feeling of satisfaction with life. Ingeborg (77) says much the same: 'If you're well, growing old isn't hard, is it? ( ...) In fact being well is a prerequisite for growing old. That you are able to walk properly, are well and don't suffer from ailments.' Ingeborg does not exercise, and has a pragmatic attitude to diet: 'If you enjoy the food you eat I think it's okay [that you eat food you like] and you don't get too fat'. Diet is not something that Ingeborg bothers about to any appreciable extent. However, she returns repeatedly to how enriching she finds the day-to-day social interaction with other older people in their local centre - 'the time we spend together there is good for our health, I think'.

Several members of this group see health less as the object of a well-planned, proactive campaign, e.g. following a carefully planned diet and exercise programme, and more a matter of not being ill. Several of them repeatedly return to the idea that social relationships with other people mean a great deal to them, and that they actively seek them out. Several of them criticised the 'health mania', which is what many of them call the great contemporary focus on health, because they think it is out of control and has displaced compassionate care and attention. Dagmar (81), for example, says that although health is important,

It isn't enough to get you through life on its own. I mean, as a person, you'll miss out on what's important in life if you only think about health - by which I mean physical health - because I think relationships, human relations, are immensely important - things like giving and receiving care.

The worship of the physical body Dagmar refers to is not, in her opinion, enough on its own as an expression of what health is. She sees reciprocal care and social relationships as the important things in life. Several other informants focused on health as an expression of the general quality of life. Quality of life refers, among other things, to satisfaction with life and self-confidence. Britta (74) says, for example:

When I think about health I think about what makes up our quality of life. That's what I associate health with. That you feel well, are mobile and not sick, you know. (...) I don't go pestering the doctor every other day to have my cholesterol and blood pressure taken and so on, because your body tells you when something's wrong, doesn't it?

Britta also sees health as being synonymous with mobility and feeling well. She keeps herself going physically by taking the stairs and cycling every so often, but does not 
seem nervous at the thought of being in the process of growing old. She tries to come to terms with her age by accepting that 'at some point I'll have to maybe stop cycling and perhaps just make do with taking the stairs, and the likes'. In a similar manner, Christian expresses a certain degree of acceptance of his own physical shortcomings: 'I can't run any more. It hurts my back, so I've had to stop. But I swim every morning, which is just as good. And it's very social as well, so that's all right, isn't it?'

\section{Scepticism about the media}

Compared to the first groupof informants described above and their faith in mediated health expertise, a pronounced scepticism about the media is the order of the day in the second group. Britta, who was just quoted, for example, thinks that the media exacerbate or even create health problems. She says: 'Nor am I the type who'll rush off to look things up online if I spot symptoms. Because if you do that you will have whatever it is! [laughs]. I'm more into just feeling and being well and mobile. That's what I associate with health.' Other informants also critiqued the way that the media handle health issues and think they have a negative effect on people. For example, Svend (76) was very angry and outraged about TV programmes about cooking because, in his opinion, they transmit conflicting information to the viewers, who will, therefore, be influenced in the wrong way. Of a very popular TV prime time cooking programme, he says:

It's filthy the way they juggle the different types of food - bacteria and the likes - you should be properly hygienic if you're on the telly, and they just aren't, so I can't be bothered watching it anymore. And then the food isn't always healthy either. The chances are that it is unhealthy. And if you happen to be in any doubt, just look at the presenters.

Like Svend, several of the informants point out that the media have a major responsibility for conveying information about health in a manner that is not misleading or directly contrary to general recommendations issued by the health authorities. Their mistrust of the media arises from a lack of transparency, which makes them doubt the credibility of the mediated expertise. Dagmar puts her confusion into words:

For many years, I bought the women's magazine, Søndag, and they have a whole section in the middle of every edition all about health. Part of me thinks that's fine, and they do try to be serious - it's proper information, written by doctors and the like. But it's still confusing because the messages change. Take diet for example. Do this. Don't do that. Okay, now you can do it again. No, you really don't know whether you're coming or going. I find it interesting but it's too much.

Britta expresses a similar scepticism and ambivalence and points out the frustration to which the media give rise because, as she sees them, they are the reason she finds it difficult to make an informed choice:

One day this is healthy, the next day that. And then it all changes, and so on, and so on (...) if you take it all seriously. Me, I'm just thinking - well if you don't die of it, you'll die of something else, won't you? So I have a bit of a relaxed attitude to the stuff the media puts out. 
With the statement 'if you don't die of it, you'll die of something else' Britta gives vent to both irony and powerlessness. She exemplifies a dilemma expressed by several of the informants. On the one hand, they yearn for knowledge and would like to follow the experts' recommendations, but on the other hand, they do not feel that they can make informed choices, since the knowledge available to them in the media is imprecise and lacks credibility. However, the fatalistic attitude several of them express should not be mistaken for indifference. Rather, it is an expression of the powerlessness that they feel about being made personally responsible for their own health (see also Lupton 2012: 103). On the one hand, they feel left in the lurch by the many contradictory messages in the media but, on the other hand, their critique in itself bears witness to their attempts, albeit in vain, to understand the health advice proffered by the media.

Unlike some of the other informants who, as mentioned earlier, have faith in the media and throw themselves into new experiments with both diet and exercise, this group's attitude to the media is highly sceptical but also characterised by a more traditional recipient awareness, by virtue of which they expect to receive clear and reliable answers they can use to inform themselves and their own decisions. They expect the media to cite authoritative sources, which in their eyes means in particular doctors of various types, and they expect that the media will actually be able to vouch for their health recommendations and not change their mind from one day to the next.

They cannot be bought off with any health story in the media or, as Britta puts it: 'They shouldn't just try to fob me off with any old stuff. I want to decide for myself what I consume and what I don't want to consume', which testifies to both scepticism about the general health mania she thinks characterises the media, and to an attempt to carve out a certain degree of autonomy. She does not feel associated with the consensus about health as if it is just a matter of wanting to experiment with your lifestyle. Britta points out that: 'It's a matter of feeling good about yourself and not going about thinking about what you should do in case of this, that and the other, you know? Because that can be stressful.' Britta and several other informants adhere to the idea that it is the voice of more traditional, science-based expertise that should be the recurring one in the media when it comes to health recommendations, and not what ordinary people agree from time to time constitutes a healthy lifestyle.

Despite the criticism of the media's changing health recommendations, this group's views nevertheless show that the media's 'health fad', as one of them calls it, does in fact play a role for them as something they have to relate to all the time but also something they feel 'left behind' by. Even though they share concerns about the fluctuating nature of health recommendations in the media, they have, conversely, a great deal of confidence in their own ability to find the 'solution' that is best for them based on what several of them call 'common sense' - 'I'll do what I've always done and it'll be fine'. In this situation, their lifelong experience helps them when they decide to be pragmatic about how much influence they want to allow the media to exert on their lives; but they also stress that it annoys them that the world around them - in this case the media - expects them to make judgements and be constantly ready to revise what they think is best and the right thing to do in terms of health. 


\section{Conclusion}

The study shows that ideas about active and healthy ageing are something that all older people relate to. In this sense, 'willingness to be healthy' (Higgs et al. 2009) is considered by the elderly informants in this study to be the same as striving for 'the good old age'. For these older people, showing that you have the will to be healthy means thinking about your own ageing process and the obligation to forge a good and healthy life for yourself. Everybody wants to be active and keep going, but some are more accepting than others of the fact that the body ages, and some allow mediated health content to influence their lives more than others.

The study reveals dilemmas associated with the way in which people are made responsible for their own health and ageing. These dilemmas are related, in particular, to the role of the media and their expertise as authoritative voices to whom the elderly will actually listen. Some older people think that health coverage in the media, in all its often contradictory diversity, is basically positive, and use it as a kind of guide to practising a healthy and active lifestyle and as a means of perpetuating the feeling that it is possible, but also required of them, to change in order to keep up with the times. For this group, the influence of the media strengthens their sense of remaining an active part of society. Their readiness to experiment with their bodies and lifestyles in the name of health is, in itself, proof that age does not yet have them in its grip.

Others adopt a more critical approach to the way in which the media cover health. They think health has been accorded the status of a more or less random lifestyle fad. This group has relatively high expectations of the media as communicators you ought to be able to trust, e.g. Svend, who thinks that various TV programmes directly contradict recommendations on food and hygiene issued by the health authorities. They critique the media's lack of responsibility and feel frustrated at being left to make the best health choices on their own. Some informants also find it tiresome that they cannot pinpoint the sources behind the media's health discourse, which they consider, conversely, to be an annoying extra pressure on their way of thinking about their own lives. For some of them, this results in a paradoxical sense of rebellious powerlessness. For others, it results in them reflecting on active ageing, in which diet and exercise may be considered important, but they adhere more strictly to the vision of health as related to social interaction with other people. They have both a pragmatic attitude toward the influence that the media exerts on their lives as well as a certain degree of optimism about the future - something lacking, at least during these interviews, among the group with a dedicated approach to media output about health who try to improve and optimise their bodies and prevent the risks that they feel are associated with growing old.

Returning to Meyrowitz's (1985) point about an 'all-age' lifestyle, in which the older have greater access to lifestyles previously associated with earlier phases of life, this study confirms that, nowadays, late life offers a wealth of options and that the older can still 'grow' because life is in no sense over just because you are in one of its later stages. Anybody who thinks that the older are inactive or have come to a halt will find that this study disproves that notion. It is not the image that the older people have of themselves. The informants live many different types of active late life. The media plays an important role as both an innovative and changing tool to guide lifestyles that underpin the ideals of normal ageing - and as a source of inspiration. Although the media sometimes send mixed signals, and therefore cannot be used as a guide for health, it functions as 
a kind of 'negotiating partner' in the process of growing older and trying to reconcile yourself with that fact. Finally, the study also shows that late life is characterised by a continuous need to exercise autonomous authority over the self, and that late life is not a 'free' age, where you just sit back and relax.

\section{References}

Alftberg, Åsa \& Lundin, Susanne (2012). Successful Ageing in Practice: Reflections on Health, Activity and Normality in Old Age in Sweden. Culture Unbound: Journal of Current Cultural Research, 4(3): 481-497.

Brinkmann, Svend (2014). Det kvalitative interview. København: Hans Reitzels Forlag

Christensen, Christa Lykke (2016). The Mediatization of Health Expertise. Critical Studies of Television: The International Journal of Television Studies, 11(2): 204-216.

Christensen, Kaare et al. (2013). Flere overlever til de højeste aldre og med bedre funktionsevne. Ugeskrift for Loger, 175(41).

Danish Agency for Culture (2015). Rapportering om mediernes udvikling i Danmark. Copenhagen: Danish Agency for Culture.

Entman, Robert M. (1993). Framing. Toward Clarification of a Fractured Paradigm. Journal of Communication, 43(4): 51-58.

Featherstone, Mike \& Wernick, Andrew (eds.) (1995). Images of Aging, Cultural Representations of Later Life. London: Routledge.

Harris, Richard J. (2009). A Cognitive Psychology of Mass Communication. London: Routledge.

Henwood, Flis; Wyatt, Sally; Hart, Angie \& Smith, Julie (2003). 'Ignorance is Bliss Sometimes': Constraints on the Emergence of the 'Informed Patient' in the Changing Landscapes of Health Information. Sociology of Health \& Illness, 25(6): 589-607.

Hepworth, Mike (2004). Images of Old Age, pp. 3-29, in Jon F. Nussbaum and Justine Coupland (eds.) Handbook of communication and aging research. London: Lawrence Erlbaum Associates Publishers.

Higgs, Paul; Leontowitsch, Miranda; Stevenson, Fiona \& Jones, Ian Rees (2009). Not Just Old and Sick - the 'Will to Health' in Later Life. Age and Society, 29(5): 687-707.

Hjarvard, Stig (2016). Mediatization and the Changing Authority of Religion. Media, Culture \& Society, 38(1): 8-17.

Jeune, Bernard; Lindholm Eriksen, Mette; Andersen-Ranberg, Karen \& Brønnum-Hansen, Henrik (2015). Improvement in Health Expectancy at Ages 50 and 65 in Denmark During the Period of 2004-2011. Scandinavian Journal of Public Health, 43(3): 254-259.

Katz, Stephen (2000). Busy Bodies: Activity, Aging and the Management of Everyday Life. Journal of Aging Studies, 14(2): 135-52.

Katz, Stephen and Marshall, Barbara (2003). New Sex for Old: Lifestyle, Consumerism, and the Ethics of Aging Well. Journal of Aging Studies, 17(1): 3-16.

Kvale, Steinar (2007). Doing Interviews. London: Sage.

Lewis, Tania (2006). Seeking Health Information on the Internet: Lifestyle Choice or a Bad Attack of Cyberchondria? Media, Culture \& Society, 28(4): 521-539.

Lewis, Tania (2008). Smart Living: Lifestyle Media and Popular Expertise. New York: Peter Lang.

Lupton, Deborah (2012). Medicine as Culture. London: Sage.

Marshall, Barbara and Rahman, Momin (2015). Celebrity, Ageing and the Construction of 'Third Age' Identities. International Journal of Cultural Studies, 18(6): 577-593.

McCombs, Maxwell E. (2014). Setting the Agenda: The Mass Media and Public Opinion. Cambridge: Polity.

Meyrowitz, Joshua (1985). No Sense of Place. Oxford: Oxford University Press.

Morgan, Michael; Shanahan, James and Signorielli, Nancy (eds.) (2012). Living with Television Now: Advances in Cultivation Theory \& Research. New York: Peter Lang.

Nielsen, Rasmus Kleist \& Schrøder, Kim (2014). Danskernes brug af digitale medier og nyheder i 2014. Roskilde: Roskilde University.

Otto, Lene (1997). Sundhedsbegrebets omfang og opløsning. En strukturel analyse af sundhedsdiskursen, in Hansen, Helle Plough \& Ramhøj, Pia (eds.) Tvarvidenskabelige perspektiver på sundhed og sygdom. Copenhagen: Akademisk Forlag.

Rozanova, Julia (2010). Discourses of Successful Aging in The Globe \& Mail: Insights from Critical Gerontology. Journal of Aging Studies, 24(4): 213-222. 
Thagaard, Tove (1998). Systematikk og innlevelse. En innføring i kvalitativ metode. Bergen: Fagbokforlaget. Wien, Charlotte (2005). Ældrebilledet i medierne gennem 50 år. En undersøgelse af ældrestereotyper i dagbladene fra 1953 til 2003. København: Socialministeriet.

Williams, Angie; Wadleigh, Paul Mark and Ylänne, Virpi (2010). Images of Older People in UK Magazine Advertising: Toward a typology. International Journal of Aging and Human Development, 71(2): 83-114. 